\title{
Specific Health Knowledge and Health Literacy of Patients before and after Bariatric Surgery: A Cross-Sectional Study
}

\author{
Hinrich Köhler ${ }^{a}$ Renata Dorozhkina ${ }^{a}$ Kerstin Gruner-Labitzke ${ }^{a}$ \\ Martina de Zwaan ${ }^{b}$ \\ a Department of General, Abdominal, and Bariatric Surgery, Herzogin Elisabeth Hospital, \\ Braunschweig, Germany; ${ }^{b}$ Department of Psychosomatic Medicine and Psychotherapy, \\ Hannover Medical School, Hannover, Germany
}

\author{
Keywords \\ Specific knowledge $\cdot$ Bariatric surgery $\cdot$ Metabolic surgery $\cdot$ Patient education
}

\begin{abstract}
Background: It is an important condition for adequate weight loss and prevention of adverse events that bariatric surgery (BS) candidates possess good specific health knowledge. There is a paucity of standardized instruments to evaluate the specific health knowledge of patients before and after BS. Therefore, we developed a 32-item multiple-choice test covering the main aspects of life which are important after BS, and investigated the correlation of specific health knowledge with health literacy, level of depression and anxiety, percentage of excess weight loss, and specific complications of BS in postoperative patients. Methods: Two groups participated in the cross-sectional study: the preoperative group $(n=109)$ was recruited from candidates for BS (gastric bypass or sleeve gastrectomy), the postoperative group ( $n=110$ ) was recruited from patients 12-74 months after BS (average 33 months, SD = 16.5). Both groups had completed a preoperative multimodal training program. Specific health knowledge was assessed with a newly developed knowledge questionnaire. Health literacy was evaluated with the short version of the European Health Literacy Survey (HLS-EU-Q16). The 9-item Patient Health Questionnaire (PHQ-9) and the 7-item Generalized Anxiety Scale (GAD7) were used to assess the levels of depression and anxiety. Results: The pre- and postop-
\end{abstract}

H. Köhler and R. Dorozhkina contributed equally to this work. 
erative group did not differ with regard to the number of correctly answered questions on the knowledge questionnaire, with $75 \%$ correct answers in both groups $(p=0.059)$. No correlations were found with health literacy $(p=0.498)$ and levels of depression (preoperative group: $p=0.279$; postoperative group: $p=0.242$ ) and anxiety (preoperative group: $p=0.866$; postoperative group: $p=0.119$ ). In postoperative patients specific health knowledge was not associated with the weight loss achieved $(p=0.437)$. Conclusion: The newly designed knowledge questionnaire can be useful for screening specific knowledge of BS patients at different time points.

(C) 2020 The Author(s)

Published by S. Karger AG, Basel

\section{Introduction}

Overweight and severe obesity are increasing rapidly worldwide [1]. Severe obesity is a serious disease causing numerous comorbidities and reducing life expectancy [2]. Surgery results in greater improvement in weight loss outcomes and weight-associated comorbidities compared with nonsurgical interventions [3]. Roux-en-Ygastric bypass and sleevegastrectomy are the most common procedures to treat patients with severe obesity both worldwide and in Germany [4, 5]. The average percentage of excess weight loss (\%EWL) 1 year after surgery is about $70 \%$ for gastric bypass [6] and 65\% for sleeve gastrectomy [7], but about one-third of patients show failure with $<50 \%$ EWL [8] or weight regain in long-term evaluations [9].

Long-term outcome not only depends on the correctly performed surgery, but also on education, specific health knowledge, and health literacy of the patients [10]. Furthermore, weight loss surgery leads to significant changes in the anatomy and physiology of the gastrointestinal tract and of digestion. Therefore, patients need training, support, and assessment for sufficient supplementation [11]. Patient motivation and adherence to instructions are crucial for overall outcome [12]. An impact of depression and anxiety on the long-term success of bariatric surgery (BS) has also been demonstrated [13].

It is an important condition for adequate weight loss and prevention of adverse events that BS candidates possess good specific health knowledge. There is a paucity of standardized instruments to evaluate specific health knowledge of patients before and after bariatric and metabolic surgery. Therefore, we developed a multiple-choice test focusing on the main aspects of life important after bariatric and metabolic surgery (lifestyle, nutrition, follow-up visits, side effects, and supplementation).

The purpose of this study was to collect data on individual patients' specific health knowledge before and after weight loss surgery and to investigate the association with weight loss, incidence of postoperative complications, health literacy, depression, and anxiety.

\section{Methods}

\section{Preoperative Multimodal Training Program}

The Department of General, Abdominal, and Bariatric Surgery of Herzogin Elisabeth Hospital Braunschweig provides a mandatory preoperative multimodal training program including behavioral training, dietary modification, and exercise for all BS candidates. The course (12 sessions, 90 min a week) is held by specially trained dieticians, surgeons, and psychologists with a maximum of 12 participants. The course requires reflection on previous actions for weight control and individual eating habits, demonstrating alternatives as appropriate. Furthermore, the participants learn the basics of food science to optimize their nutritional behavior and food-purchasing behavior. Mandatory individual weekly plans are used 
to promote leisure and dietary habits that maximize the positive effects of daily physical activity and of appropriate nutrition, respectively. The psychological training component of the course provides individual methods to break the vicious circle of deficient self-esteem, negative self-perception, social withdrawal, and lack of exercise, which are relevant to the origin and treatment of addiction behavior and to the individual disorder history.

All participants get comprehensive information about healthy nutrition and special recommendations for the pre- and postoperative period. Candidates for surgery receive handouts about long-term supplementation of vitamins, minerals, and protein. Participants get instructions how to cope with the most common complications or syndromes such as food intolerance or food bolus obstruction, dehydration, constipation, dumping syndrome, and epigastric pain.

\section{Study Design}

If knowledge gaps were identified during the study (multiple-choice tests), candidates were offered additional explanations by the interviewer. Questionnaire data were pseudonymized and personal data were secured.

\section{Recruitment}

The data were collected between December 2015 and July $2016(n=219)$. The preoperative group $(n=109)$ was recruited from candidates for obesity surgery (gastric bypass or sleeve gastrectomy). The questionnaires were given to the patients during the preoperative week or latest on the second postoperative day. The postoperative group $(n=110)$ was recruited from patients 12-74 months after gastric bypass or sleeve gastrectomy (average 33 months, SD = 16.5). Postoperative patients were recruited during follow-up visits (50\%), during appointments with the plastic surgeon (21.8\%), during inpatient treatment because of adverse events (21.8\%), or during other visits (6.4\%). All participants had successfully completed the preoperative mandatory multimodal training program. Exclusion criteria were insufficient German language skills, incomplete participation in the multimodal training program, and former obesity surgery.

\section{Measurements}

The specific health knowledge of the patients before and after BS was evaluated with a newly designed knowledge questionnaire. Developed by the bariatric team (surgeons, dieticians, psychologists, and bariatric nurses), the test consists of 32 multiple-choice questions with five possible answers, only one of which is correct. Patients receive one point for each correctly answered question. Zero points are given for each incorrectly answered question or missing response. A total score is calculated in the range from 0 to 32 points, the higher scores corresponding to a better specific knowledge. The test deals with important aspects of life after bariatric and metabolic surgery such as lifestyle changes, follow-up visits, potential complications, effects and side-effects, supplementation, as well as nutritional and technical aspects of the surgery. To investigate the validity of the newly developed questionnaire, 10 candidates of bariatric and metabolic surgery were piloted. According to patient feedback all questions and formulations were easy to understand. The complexity of the test was considered not to be difficult by these patients. The complete questionnaire is available from Köhler et al. [14].

Health literacy was evaluated with the short version of the European Health Literacy Survey (HLS-EU-Q16) [15]. This instrument consists of 16 items, each with four steps from very easy to very difficult. It includes 12 dimensions of health literacy, concerning therapy and treatment, prevention and health promotion, as well as stages of processing healthrelevant information such as access, understanding, assessment, and application. A HLS- 
Table 1. Sociodemographic characteristics of the study population comparing pre- and postoperative patients

\begin{tabular}{|c|c|c|c|c|}
\hline Variables & $\begin{array}{l}\text { Total } \\
(n=219)\end{array}$ & $\begin{array}{l}\text { Preoperative } \\
(n=109)\end{array}$ & $\begin{array}{l}\text { Postoperative } \\
(n=110)\end{array}$ & $\begin{array}{l}\text { Statistical } \\
\text { analysis, } \\
t \text { and } \chi^{2} \text { test }\end{array}$ \\
\hline Age, years & $42.8 \pm 12.2$ & $40.7 \pm 12.7$ & $44.9 \pm 11.4$ & $\begin{array}{l}t=-2.604 \\
\mathrm{df}=217 \\
p=0.01\end{array}$ \\
\hline BMI & $39.0 \pm 9.9$ & $46.9 \pm 7.3$ & $31.9 \pm 6.6$ & $\begin{array}{l}t=15.217 \\
\mathrm{df}=217 \\
p<0.001\end{array}$ \\
\hline Female sex & $80.4 \%(176)$ & $76.1 \%(83)$ & $84.5 \%(93)$ & $\begin{array}{l}\chi^{2}=2.447 \\
\mathrm{df}=1 \\
p=0.118\end{array}$ \\
\hline Marital status & & & & $\chi^{2}=7.724$ \\
\hline Single & $23.2 \%(51)$ & $30.3 \%(33)$ & $16.4 \%(18)$ & $\mathrm{df}=4$ \\
\hline Partnership & $11.0 \%(24)$ & $11.0 \%(12)$ & $10.9 \%(12)$ & $p=0.102$ \\
\hline Married & $56.2 \%(123)$ & $51.4 \%(56)$ & $60.9 \%(67)$ & \\
\hline Separated & $8.2 \%(18)$ & $5.5 \%(6)$ & $10.9 \%(12)$ & \\
\hline Widowed & $1.4 \%(3)$ & $1.8 \%(2)$ & $0.9 \%(1)$ & \\
\hline High school graduate & & & & $\chi^{2}=3.318$ \\
\hline No & $72.6 \%(159)$ & $69.6 \%(75)$ & $76.3 \%(84)$ & $\mathrm{df}=7$ \\
\hline Yes or more & $26.6 \%(58)$ & $29.4 \%(32)$ & $23.6 \%(26)$ & $p=0.801$ \\
\hline Employed & $66.8 \%(145)$ & $67.9 \%(74)$ & $65.7 \%(71)$ & $\begin{array}{l}\chi^{2}=0.113 \\
\mathrm{df}=1 \\
p=0.737\end{array}$ \\
\hline Surgery & & & & $\chi^{2}=0.836$ \\
\hline Gastric bypass & $82.2 \%(180)$ & $79.8 \%(87)$ & $84.5 \%(93)$ & $\mathrm{df}=1$ \\
\hline Sleeve gastrectomy & $17.8 \%(39)$ & $20.2 \%(22)$ & $15.5 \%(17)$ & $p=0.360$ \\
\hline
\end{tabular}

Values are presented as mean \pm SD or $\%(n)$.

EU-Q16 index with three different levels can be rated as "inadequate," "problematic," and "sufficient" health literacy.

Symptoms of depression were assessed with the German version of the 9-item Patient Health Questionnaire (PHQ-9) [16]. Each item is scored from 0 to 3, yielding a total score between 0 and 27 . A total score $\geq 10$ indicates the presence of major depressive disorder. The PHQ-9 has been validated in BS patient populations [17]. The internal consistency of the depression module (Cronbach's $\alpha$ ) in our samples was 0.849 .

Symptoms of anxiety were assessed with the German version of the 7-item Generalized Anxiety Scale (GAD-7) [18, 19]. The GAD-7 was designed to identify patients with generalized anxiety disorder and to assess the severity of anxiety. The scale consists of seven items. A score $>10$ indicates the diagnosis of a clinically relevant anxiety disorder. The internal consistency (Cronbach's $\alpha$ ) in our samples was 0.893 .

The data about specific postoperative complications, such as dumping syndrome and anastomotic ulcer, were collected from medical records, follow-up contacts, and patient questionnaire. 
Köhler et al.: Specific Health Knowledge of Patients before and after Bariatric Surgery

Table 2. Knowledge test, health literacy, and levels of depression and anxiety

\begin{tabular}{|c|c|c|c|c|}
\hline Variables & $\begin{array}{l}\text { Total } \\
(n=219)\end{array}$ & $\begin{array}{l}\text { Preoperative } \\
(n=109)\end{array}$ & $\begin{array}{l}\text { Postoperative } \\
(n=110)\end{array}$ & $\begin{array}{l}\text { Statistical } \\
\text { analysis, } \\
t \text { and } \chi^{2} \text { test }\end{array}$ \\
\hline $\begin{array}{l}\text { Number of correctly answered } \\
\text { questions (max. 32) }\end{array}$ & $23.9 \pm 4.3$ & $24.5 \pm 4.2$ & $23.4 \pm 4.4$ & $\begin{array}{l}t=1.900 \\
\mathrm{df}=217 \\
p=0.059\end{array}$ \\
\hline $\begin{array}{l}\text { Health literacy } \\
\text { (HLS-EU-Q16 total value) }\end{array}$ & $14.1 \pm 2.5$ & $14.2 \pm 2.2$ & $13.9 \pm 2.8$ & $\begin{array}{l}t=0.697 \\
\mathrm{df}=209 \\
p=0.486\end{array}$ \\
\hline $\begin{array}{l}\text { Level of anxiety } \\
\text { (GAD-7 total value) }\end{array}$ & $4.2 \pm 4.2$ & $3.6 \pm 3.5$ & $4.9 \pm 4.7$ & $\begin{array}{l}t=-2.121 \\
\mathrm{df}=210 \\
p=0.035\end{array}$ \\
\hline $\begin{array}{l}\text { Level of depression } \\
\text { (PHQ-9 total value) }\end{array}$ & $4.9 \pm 4.5$ & $4.4 \pm 4.0$ & $5.6 \pm 4.9$ & $\begin{array}{l}t=-1.861 \\
\mathrm{df}=206 \\
p=0.064\end{array}$ \\
\hline $\begin{array}{l}\text { Anxiety } \\
\text { (GAD-7 cutoff } \geq 10 \text { ) }\end{array}$ & $10.4 \%$ (22) & $6.5 \%(7)$ & $14.4 \%$ (15) & $\begin{array}{l}\chi^{2}=3.593 \\
\mathrm{df}=1 \\
p=0.058\end{array}$ \\
\hline $\begin{array}{l}\text { Depression } \\
\text { (PHQ-9 cutoff } \geq 10 \text { ) }\end{array}$ & $14.8 \%(31)$ & $10.2 \%(11)$ & $19.6 \%$ (20) & $\begin{array}{l}\chi^{2}=3.701 \\
\mathrm{df}=1 \\
p=0.054\end{array}$ \\
\hline
\end{tabular}

Values are presented as mean \pm SD or \% (n). GAD-7, 7-item Generalized Anxiety Scale; HLS-EU-Q16, European Health Literacy Survey (short version); PHQ-9, 9-item Patient Health Questionnaire.

\section{Statistical Analysis}

Data analyses were performed using the IBM Statistical Package for Social Sciences (SPSS, version 22.0). The pre- and postoperative groups were compared. For comparison of continuous variables, $t$ tests for independent samples were used; for comparison of categorical variables, $\chi^{2}$ tests were applied. For assessment of correlations between variables, Pearson correlation coefficients were used. Statistical significance was determined for $p$ values $<0.05$.

\section{Results}

Descriptive Characteristics of Pre- and Postoperative Patients

A total of $80.4 \%$ of the participants were female and $19.6 \%$ were male. The groups differed significantly in age and BMI but not in other sociodemographic variables as summarized in Table 1. The distribution of the type of surgery did not differ between the pre- and postoperative groups. The mean follow-up since surgery in the postoperative group was $32.9 \pm 16.5$ months. More than $95 \%$ of postoperative participants claimed that they completely or partly adhered to the dietary recommendations and $80 \%$ reported to continue with physical exercises.

\section{Specific Health Knowledge and Health Literacy}

The pre- and postoperative groups did not differ with regard to the total number of correctly answered questions on the knowledge test (Table 2). The average number of correct 
Table 3. Number of correctly answered questions

\begin{tabular}{|c|c|c|c|c|c|}
\hline & Questions & $\begin{array}{l}\text { Total } \\
(n=219)\end{array}$ & $\begin{array}{l}\text { Preoperative } \\
(n=109)\end{array}$ & $\begin{array}{l}\text { Postoperative } \\
(n=110)\end{array}$ & $\begin{array}{l}\text { Statistical } \\
\text { analysis, } \chi^{2}\end{array}$ \\
\hline 1 & $\begin{array}{l}\text { Lifelong necessity to follow } \\
\text { dietary recommendations }\end{array}$ & $87.7 \%(192)$ & $92.7 \%(101)$ & $82.7 \%(91)$ & $\begin{array}{l}\chi^{2}=5.363 \\
\mathrm{df}=2 \\
p=0.068\end{array}$ \\
\hline 2 & $\begin{array}{l}\text { Complication caused by } \\
\text { smoking }\end{array}$ & $83.1 \%(182)$ & $86.2 \%(94)$ & $80.0 \%(88)$ & $\begin{array}{l}\chi^{2}=2.527 \\
\mathrm{df}=2 \\
p=0.283\end{array}$ \\
\hline 3 & Dietary change after surgery & $93.6 \%(205)$ & $97.2 \%(106)$ & $90.0 \%(99)$ & $\begin{array}{l}\chi^{2}=5.235 \\
\mathrm{df}=2 \\
p=0.073\end{array}$ \\
\hline 4 & $\begin{array}{l}\text { Medication to prevent gastric } \\
\text { ulcer }\end{array}$ & $76.3 \%(167)$ & $67.9 \%(74)$ & $84.5 \%(93)$ & $\begin{array}{l}\chi^{2}=8.389 \\
\mathrm{df}=2 \\
p=0.015\end{array}$ \\
\hline 5 & Need of long-term follow-up & $96.8 \%(212)$ & $99.1 \%(108)$ & $94.5 \%(104)$ & $\begin{array}{l}\chi^{2}=3.738 \\
\mathrm{df}=2 \\
p=0.154\end{array}$ \\
\hline 6 & $\begin{array}{l}\text { Dealing with complaints after } \\
\text { surgery }\end{array}$ & $84.0 \%(184)$ & $83.5 \%(91)$ & $84.5 \%(93)$ & $\begin{array}{l}\chi^{2}=1.135 \\
\mathrm{df}=2 \\
p=0.567\end{array}$ \\
\hline 7 & $\begin{array}{l}\text { Effect of physical activity } \\
\text { after surgery }\end{array}$ & $95.0 \%(208)$ & $94.5 \%(103)$ & $95.5 \%(105)$ & $\begin{array}{l}\chi^{2}=0.106 \\
\mathrm{df}=1 \\
p=0.745\end{array}$ \\
\hline 8 & $\begin{array}{l}\text { Reasons for dumping } \\
\text { syndrome }\end{array}$ & $77.6 \%(170)$ & $83.5 \%(91)$ & $71.8 \%(79)$ & $\begin{array}{l}\chi^{2}=7.429 \\
\mathrm{df}=2 \\
p=0.024\end{array}$ \\
\hline 9 & $\begin{array}{l}\text { Typical complaints of } \\
\text { dumping syndrome }\end{array}$ & $32.0 \%(70)$ & $29.4 \%(32)$ & $34.5 \%(39)$ & $\begin{array}{l}\chi^{2}=0.844 \\
\mathrm{df}=2 \\
p=0.656\end{array}$ \\
\hline 10 & Side effects of gastric bypass ${ }^{1}$ & $37.9 \%(83)$ & $34.9 \%(38)$ & $40.9 \%(45)$ & $\begin{array}{l}\chi^{2}=4.036 \\
\mathrm{df}=2 \\
p=0.133\end{array}$ \\
\hline 11 & $\begin{array}{l}\text { Need for supplementation of } \\
\text { vitamins and minerals }\end{array}$ & $98.6 \%(216)$ & $99.1 \%(108)$ & $98.2 \%(108)$ & $\begin{array}{l}\chi^{2}=0.329 \\
\mathrm{df}=1 \\
p=0.566\end{array}$ \\
\hline 12 & $\begin{array}{l}\text { Recommended vitamins after } \\
\text { surgery }\end{array}$ & $89.5 \%(196)$ & $87.2 \%(95)$ & $91.8 \%(101)$ & $\begin{array}{l}\chi^{2}=1.653 \\
\mathrm{df}=2 \\
p=0.438\end{array}$ \\
\hline 13 & $\begin{array}{l}\text { Vitamin that needs to be } \\
\text { injected }\end{array}$ & $93.2 \%(204)$ & $88.1 \%(96)$ & $98.2 \%(108)$ & $\begin{array}{l}\chi^{2}=8.773 \\
\mathrm{df}=2 \\
p=0.012\end{array}$ \\
\hline 14 & $\begin{array}{l}\text { Recommended minerals after } \\
\text { surgery }\end{array}$ & $69.4 \%(152)$ & $54.1 \%(59)$ & $84.5 \%(93)$ & $\begin{array}{l}\chi^{2}=26.550 \\
\mathrm{df}=2 \\
p<0.001\end{array}$ \\
\hline 15 & $\begin{array}{l}\text { Eating and drinking } \\
\text { immediately after surgery }\end{array}$ & $95.0 \%(208)$ & $96.3 \%(105)$ & $93.6 \%(103)$ & $\begin{array}{l}\chi^{2}=0.833 \\
\mathrm{df}=1 \\
p=0.361\end{array}$ \\
\hline
\end{tabular}


Table 3 (continued)

\begin{tabular}{|c|c|c|c|c|c|}
\hline & Questions & $\begin{array}{l}\text { Total } \\
(n=219)\end{array}$ & $\begin{array}{l}\text { Preoperative } \\
(n=109)\end{array}$ & $\begin{array}{l}\text { Postoperative } \\
(n=110)\end{array}$ & $\begin{array}{l}\text { Statistical } \\
\text { analysis, } \chi^{2}\end{array}$ \\
\hline 16 & Drinking after surgery & $79.5 \%(174)$ & $82.6 \%(90)$ & $76.4 \%(84)$ & $\begin{array}{l}\chi^{2}=1.291 \\
\mathrm{df}=1 \\
p=0.256\end{array}$ \\
\hline 17 & $\begin{array}{l}\text { Beverages recommended } \\
\text { after surgery }\end{array}$ & $78.5 \%(172)$ & $8.4 \%(92)$ & $72.7 \%(80)$ & $\begin{array}{l}\chi^{2}=6.094 \\
\mathrm{df}=2 \\
p=0.048\end{array}$ \\
\hline 18 & $\begin{array}{l}\text { Meals recommended after } \\
\text { surgery }\end{array}$ & $78.5 \%(172)$ & $87.2 \%(95)$ & $70.0 \%(77)$ & $\begin{array}{l}\chi^{2}=9.923 \\
\mathrm{df}=2 \\
p=0.007\end{array}$ \\
\hline 19 & $\begin{array}{l}\text { Daily protein requirement } \\
\text { after surgery }\end{array}$ & $70.8 \%(155)$ & $73.4 \%(80)$ & $68.2 \%(75)$ & $\begin{array}{l}\chi^{2}=1.770 \\
\mathrm{df}=2 \\
p=0.413\end{array}$ \\
\hline 20 & $\begin{array}{l}\text { Food recommended to meet } \\
\text { protein demand }\end{array}$ & $95.9 \%(210)$ & $96.3 \%(105)$ & $95.5 \%(105)$ & $\begin{array}{l}\chi^{2}=0.995 \\
\mathrm{df}=2 \\
p=0.608\end{array}$ \\
\hline 21 & $\begin{array}{l}\text { Carbohydrate intake after } \\
\text { surgery }^{1}\end{array}$ & $60.7 \%(133)$ & $64.2 \%(70)$ & $57.3 \%(63)$ & $\begin{array}{l}\chi^{2}=1.256 \\
\mathrm{df}=2 \\
p=0.534\end{array}$ \\
\hline 22 & $\begin{array}{l}\text { Alcohol consumption after } \\
\text { surgery }^{1}\end{array}$ & $36.5 \%(80)$ & $36.7 \%(40)$ & $36.4 \%(40)$ & $\begin{array}{l}\chi^{2}=0.724 \\
\mathrm{df}=2 \\
p=0.696\end{array}$ \\
\hline 23 & $\begin{array}{l}\text { Food not recommended after } \\
\text { surgery }\end{array}$ & $98.2 \%(215)$ & $99.1 \%(108)$ & $97.3 \%(107)$ & $\begin{array}{l}\chi^{2}=1.333 \\
\mathrm{df}=2 \\
p=0.513\end{array}$ \\
\hline 24 & Eating behavior after surgery & $89.5 \%(196)$ & $92.7 \%(101)$ & $86.4 \%(95)$ & $\begin{array}{l}\chi^{2}=2.758 \\
\mathrm{df}=2 \\
p=0.252\end{array}$ \\
\hline 25 & $\begin{array}{l}\text { What is removed by gastric } \\
\text { bypass }\end{array}$ & $69.9 \%(153)$ & $75.2 \%(82)$ & $64.5 \%(71)$ & $\begin{array}{l}\chi^{2}=6.215 \\
\mathrm{df}=2 \\
p=0.045\end{array}$ \\
\hline 26 & Questions about laparoscopy & $83.1 \%(182)$ & $83.5 \%(91)$ & $82.7 \%(91)$ & $\begin{array}{l}\chi^{2}=2.521 \\
\mathrm{df}=2 \\
p=0.283\end{array}$ \\
\hline 27 & $\begin{array}{l}\text { What happens to the stomach } \\
\text { by gastric bypass }\end{array}$ & $57.5 \%(126)$ & $63.3 \%(69)$ & $51.8 \%(57)$ & $\begin{array}{l}\chi^{2}=4.451 \\
\mathrm{df}=3 \\
p=0.217\end{array}$ \\
\hline 28 & $\begin{array}{l}\text { Number of anastomoses in } \\
\text { gastric bypass surgery }\end{array}$ & $41.6 \%(91)$ & $46.8 \%(51)$ & $36.4 \%(40)$ & $\begin{array}{l}\chi^{2}=2.468 \\
\mathrm{df}=2 \\
p=0.291\end{array}$ \\
\hline 29 & $\begin{array}{l}\text { Number of anastomoses in } \\
\text { sleeve gastrectomy }{ }^{1}\end{array}$ & $51.1 \%(112)$ & $59.6 \%(65)$ & $42.7 \%(47)$ & $\begin{array}{l}\chi^{2}=6.262 \\
\mathrm{df}=2 \\
p=0.044\end{array}$ \\
\hline
\end{tabular}


Table 3 (continued)

\begin{tabular}{|c|c|c|c|c|c|}
\hline & Questions & $\begin{array}{l}\text { Total } \\
(n=219)\end{array}$ & $\begin{array}{l}\text { Preoperative } \\
(n=109)\end{array}$ & $\begin{array}{l}\text { Postoperative } \\
(n=110)\end{array}$ & $\begin{array}{l}\text { Statistical } \\
\text { analysis, } \chi^{2}\end{array}$ \\
\hline 30 & Ability to undo the surgery & $68.0 \%$ (149) & $77.1 \%$ (84) & $59.1 \%(65)$ & $\begin{array}{l}\chi^{2}=25.485 \\
\mathrm{df}=3 \\
p<0.001\end{array}$ \\
\hline 31 & $\begin{array}{l}\text { Improvement of } \\
\text { comorbidities }^{1}\end{array}$ & $50.7 \%(111)$ & $48.6 \%(53)$ & $52.7 \%(58)$ & $\begin{array}{l}\chi^{2}=0.384 \\
\mathrm{df}=2 \\
p=0.825\end{array}$ \\
\hline 32 & $\begin{array}{l}\text { Expected weight loss with } \\
\text { gastric bypass }\end{array}$ & $70.3 \%$ (154) & $78.9 \%(86)$ & $61.8 \%(68)$ & $\begin{array}{l}\chi^{2}=15.163 \\
\mathrm{df}=2 \\
p=0.001\end{array}$ \\
\hline
\end{tabular}

Values are presented as $\%(n) .{ }^{1} \leq 50 \%$ of participants answered this question correctly.

answers in the total sample was $23.9 \pm 4.3(75 \%)$ ). There was no sex difference (preoperative group: $p=0.386, t=0.870, \mathrm{df}=107$; postoperative group: $p=0.051, t=1.633, \mathrm{df}=108$ ) in both groups. Older patients showed less specific health knowledge in both groups (preoperative group: $p=0.004$; postoperative group: $p=0.001$ ).

In the postoperative group, there was no correlation between the length of time since surgery and the number of correctly answered questions ( $p=0.081)$.

Pre- and postoperative participants had different knowledge on various aspects of the questionnaire (Table 3). Preoperative patients showed better knowledge on question 8 (reason for dumping syndrome), questions 17 and 18 (beverages and number of meals recommended after surgery), questions 25, 29, and 30 (technical aspects of gastric bypass and sleeve gastrectomy), and question 32 (degree of weight loss to be expected). Postoperative patients showed better knowledge on question 4 (medication to prevent gastric ulcer) and questions 13 and 14 (postoperative supplementation).

In some questions (9: typical complaints of dumping syndrome; 10: side effects of gastric bypass; 22: alcohol consumption after surgery; 28: number of anastomoses in gastric bypass surgery; 29: number of anastomoses in sleeve gastrectomy; 31: improvement of comorbidities) both groups showed low specific knowledge, with $<50 \%$ of the patients answering these questions correctly.

Regarding health literacy (HLS-EU-Q16), 78.7\% of the participants showed "sufficient competence," 18\% "problematic competence," and 3.3\% "inadequate performance." Health literacy did not differ between the pre- and postoperative groups (Table 2).

No correlation was found between specific health knowledge (number of correctly answered questions) and level of health literacy ( $p=0.498)$.

\section{Depression and Anxiety}

The level of depression (PHQ-9) did not differ between groups. The postoperative group showed significantly higher levels of anxiety (GAD-7) (Table 2). The number of patients above the cutoff value of 10 for depression and anxiety differed between groups: in the postoperative group there was a tendency for more participants being above the cutoff value. There were no correlations between levels of depression (preoperative group: $p=0.279$; postoperative group: $p=0.242$ ) and anxiety (preoperative group: $p=0.866$; postoperative group: $p=0.119$ ) and specific health knowledge (number of correctly answered questions). 


\section{Weight and Postoperative Complications}

Postoperatively, anastomotic ulcer was seen in 18 patients (16.4\%) and cholecystolithiasis in 18 patients $(16.4 \%)$; 38 patients (35.5\%) reported to have symptoms of dumping syndrome. A significant positive correlation was found for the incidence of dumping syndrome and the number of correctly answered questions on the knowledge test $(p=$ $0.036)$. There were no such correlations between performance in the knowledge test and the incidence of other adverse events such as anastomotic ulcer $(p=0.979)$ or cholecystolithiasis ( $p=0.887)$.

The patients in the postoperative group showed a change in BMI of $17.7 \pm 6.2$ (\%EWL of $76.5 \pm 23 \%)$. A total of 9 patients $(8.2 \%)$ showed an \%EWL of $<50 \%(22-49 \%)$, which is considered "insufficient weight loss" according to the Reinhold criteria [20]. However, there was no correlation between specific health knowledge and weight loss $(p=0.437)$.

\section{Discussion}

\section{Specific Health Knowledge}

The present study with 219 patients showed similar specific health knowledge of preand postoperative patients. An average of 75\% correct answers about important aspects of bariatric and metabolic surgery in both groups showed an acceptable knowledge among weight loss surgery candidates and sufficient retention of information in the period after preoperative training among postoperative patients. The survey also showed a high level of self-reported adherence to good health practices of postoperative patients.

Taube-Schiff et al. [21] showed contrasting findings. They used an Eating after Bariatric Surgery questionnaire with 12 questions (partly multiple-choice questions) concerning postoperative diet phases, nutritional complications, vitamin and mineral requirements, protein, portion size, and fluid requirements. The authors demonstrated an increase in knowledge over time (from the preoperative to the postoperative phase). In our sample, preoperative patients were better informed about general and theoretical aspects of BS, whereas postoperative patients showed more detailed knowledge about supplementation and medication after BS, topics they deal with every day. The reason for the lesser knowledge of older patients in both groups remains unclear.

An unexpected finding was the better specific knowledge of patients with dumping syndrome in comparison to patients without dumping syndrome. Perhaps such postoperative functional disorders forces patients to search for further information. These patients have to deal with the physiology of bypass surgery to cope with dumping every day. Interestingly, only $32 \%$ of patients in both groups correctly answered the question concerning the typical symptoms of dumping syndrome. Half of the participants believed that dumping syndrome is associated with abdominal pain.

Both groups showed low knowledge on certain questions. Nearly two-thirds of patients did not know about the accelerated effects of alcohol after gastric bypass surgery although this topic is repeatedly mentioned in the mandatory preoperative multimodal training program.

About half of the patients correctly understood the technical aspects of gastric bypass and gastric sleeve surgery. Less than $70 \%$ in both groups of patients knew which weight loss surgery can be reversed. It is noteworthy that surgical candidates have significantly better knowledge of this question compared with postoperative patients. However, the number of anastomoses performed during gastric bypass surgery was known by approximately $40 \%$ of the patients.

Only half of the patients answered correctly when asked about the effect of weight loss surgery in obesity-related disorders. Nonetheless, $70 \%$ of patients had realistic expectations 
concerning weight loss after gastric bypass surgery. In our survey, only $20 \%$ of surgery candidates and $34 \%$ of postoperative patients expected to reach normal weight. This is better than the findings of Bauchowitz et al. [22]. In their trial, only $25 \%$ of patients had accurate expectations of weight loss, with $65 \%$ of patients overestimating the degree of weight loss.

The strength of the newly developed comprehensive test reported here lies in its ability to test knowledge in aspects of life specifically important to bariatric patients. In contrast to other authors [23-26] who used true/false questions in their evaluations, we performed a multiple-choice quiz with five possible answers. Multiple-choice tests lead to better assessment of specific patient knowledge compared to true/false statements because the success rate of guessing is lower.

One limitation of the present study is the lack of a control group which did not receive any preoperative training. The knowledge of the patients without preoperative training remains unclear. In addition, we did not test the specific knowledge of the weight loss surgery candidates before receiving the educational course. Had we done this, it would still have been difficult to know what knowledge patients had acquired due to participating in the preoperative training program and the knowledge they had obtained due to self-education. The literature is not very helpful in this regard as there are only a few studies where knowledge was tested using questionnaires. These were of different design and had rather small groups of participants [22-25].

Bauchowitz et al. [22] evaluated the knowledge of 96 patients using the University of Virginia Bariatric Knowledge Scale questionnaire. The average score on the scale was $84 \%$ (range, 68-94\%). The patients showed good knowledge about the mechanism of weight loss, the possibility of postoperative regain, possible postoperative complications, and the importance of protein intake. The items most frequently answered incorrectly pertained to expected weight loss, length of hospital stay, and the importance of recognizing postoperative depression.

Ledoux et al. [24] applied a questionnaire consisting of 17 questions to assess health knowledge in 78 BS candidates. The authors observed a positive correlation between the results of the knowledge questionnaire and weight loss 12 months postoperatively.

Madan and Tichansky [23] found that in the years following surgery knowledge declined. They performed a knowledge quiz with 21 true/false questions, and only 100\% correct answers were considered a pass before surgery. More than $80 \%$ of the patients failed to achieve a pass $>1$ year after surgery. In the postoperative period of $<1$ year, the failure rate was only $36 \%$. Incorrect answers to questions about the impact and outcome of gastric bypass surgery were especially prevalent, showing that patients forgot key components of preoperative education. The authors concluded that repeated educational efforts after surgery should be mandatory.

The same group investigated weight loss in correlation to the number of correctly answered preoperative quiz questions [25]. They found no association between preoperative quiz performance and good health knowledge or weight loss. This result is consistent with the findings of the current study. We assumed better weight loss after BS in patients with higher levels of specific health knowledge or high health literacy, but our data did not support this hypothesis. Moreover, the current study does not demonstrate that low levels of health knowledge or low health literacy are features of the group of patients with insufficient weight loss, i.e., patients with $<50 \%$ EWL according to the Reinhold criteria.

Kalarchian et al. [27] performed a randomized controlled trial to evaluate the benefit of preoperative behavioral lifestyle intervention. They found a moderate improvement in weight loss 24 months after surgery in patients who did not receive the intervention program, but suggested caution in interpreting these findings because of the heterogeneity of the sample and some amount of weight loss during preoperative intervention. 
A review of the current literature [28] showed that behavioral, dietary, psychological, physical, and medical considerations can all play a role in suboptimal long-term weight loss. The authors recommend focusing on pre- and postoperative education sessions to ensure that the patient understands how the procedure works. In addition, they recommend tailored nutritional supplementation, 60 min of physical activity per day, lifelong annual medical, as well as psychological and dietary assessments [28]. Groller [29] reviewed the US practice of pre- and postoperative educational programs of accredited bariatric institutions. They found a wide variability in educational practices and stated that there is a lack of evidence-based educational programs for obesity surgery candidates. In addition, they highlighted the importance and power of support from peers [29]. Postoperative ongoing education is recommended because patients forget a lot of information in the postoperative period [23]. Good knowledge and skills are important for sufficient weight loss and reduction of adverse events; this is true for bariatric candidates as well as for postoperative patients. Nonetheless, there is a paucity of standardized instruments to evaluate specific health knowledge. When reviewing the current literature, Groller [29] identified a wide programmatic variability for educational practices in weight loss surgery patients with a low evidence base for best practice. The author stated, however, that support from peers is important.

\section{Levels of Depression and Anxiety}

In our sample of pre- and postoperative candidates there was no correlation between specific health knowledge and levels of depression and anxiety. Taube-Schiff et al. [21] showed contrasting findings. Interestingly, the patients with higher scores of depressiveness (PHQ-9) or anxiety (GAD-7) showed lower levels of nutritional knowledge postoperatively. These individuals gained little knowledge during preoperative training courses and needed special attention from the bariatric team. A repetition of training after reducing depressiveness or anxiety is recommended.

\section{Health Literacy}

More than three-quarters of the participants in our sample (78.7\%) showed "adequate health literacy," $18 \%$ were "problematic," and only $3.3 \%$ showed "inadequate health literacy." There was no difference between pre- and postoperative patients, but both groups showed a considerably better health literacy than the German adult population [15]. In the general population, 55\% were reported to have acquired "adequate," $31.9 \%$ "problematic," and $12.3 \%$ "inadequate" health literacy. A European survey also showed a high rate of inadequate health literacy (12\%) [30]. Therefore, bariatric and metabolic surgery candidates benefit from preoperative education and training programs in general, and in this study postoperative patients show good retention of information. Thus, our patients reported a high level of health literacy.

A correlation between health literacy or levels of depression and anxiety was not seen in our sample, although other authors have documented an impairment of learning in candidates with elevated scores of depression or anxiety [21].

\section{Conclusions}

The newly designed knowledge questionnaire can be useful for assessment of specific knowledge of bariatric and metabolic surgery candidates. The present study showed an "acceptable" specific knowledge of surgery candidates and good information maintenance over the years after education. "Good" specific knowledge and health literacy were neither 
associated with better weight loss nor with postoperative complications and do not replace the lifelong practical application of dietary recommendations and physical activity.

Further longitudinal studies with knowledge assessment at various time points (before the start of training, before and after the surgery) are necessary for the evaluation of retained knowledge in the same patients over time.

\section{Statement of Ethics}

The cross-sectional study was approved by the Institutional Ethics Committee of Hanover Medical School (No. 2948-2015). All participants received comprehensive explanation and gave written informed consent. No financial compensation was provided for participation. All procedures were in accordance with good clinical practice and within the Declaration of Helsinki.

\section{Disclosure Statement}

The authors declare that they have no conflict of interest.

\section{References}

1 Loveman E, Frampton GK, Shepherd J, Picot J, Cooper K, Bryant J, et al. The clinical effectiveness and costeffectiveness of long-term weight management schemes for adults: a systematic review. Health Technol Assess. 2011 Jan;15(2):1-182.

2 Kitahara CM, Flint AJ, Berrington de Gonzalez A, Bernstein L, Brotzman M, MacInnis RJ, et al. Association between class III obesity (BMI of $40-59 \mathrm{~kg} / \mathrm{m} 2$ ) and mortality: a pooled analysis of 20 prospective studies. PLoS Med. 2014 Jul;11(7):e1001673.

3 Colquitt JL, Pickett K, Loveman E, Frampton GK. Surgery for weight loss in adults. Cochrane Database Syst Rev. 2014 Aug; 8:CD003641.

4 Shoar S, Saber AA. Long-term and midterm outcomes of laparoscopic sleeve gastrectomy versus Roux-en-Y gastric bypass: a systematic review and meta-analysis of comparative studies. Surg Obes Relat Dis. 2017 Feb; 13(2):170-80.

5 Angrisani L, Santonicola A, Iovino P, Formisano G, Buchwald H, Scopinaro N. Bariatric Surgery Worldwide 2013. Obes Surg. 2015 Oct;25(10):1822-32.

6 Garg H, Priyadarshini P, Aggarwal S, Agarwal S, Chaudhary R. Comparative study of outcomes following laparoscopic Roux-en-Y gastric bypass and sleeve gastrectomy in morbidly obese patients: A case control study. World J Gastrointest Endosc. 2017 Apr; 9(4):162-70.

7 Fischer L, Hildebrandt C, Bruckner T, Kenngott H, Linke GR, Gehrig T, et al. Excessive weight loss after sleeve gastrectomy: a systematic review. Obes Surg. 2012 May;22(5):721-31.

8 Hawkins RB, Mehaffey JH, McMurry TL, Kirby J, Malin SK, Schirmer B, et al. Clinical significance of failure to lose weight 10 years after Roux-en-Y gastric bypass. Surg Obes Relat Dis. 2017 Oct;13(10):1710-6.

9 Shantavasinkul PC, Omotosho P, Corsino L, Portenier D, Torquati A. Predictors of weight regain in patients who underwent Roux-en-Y gastric bypass surgery. Surg Obes Relat Dis. 2016 Nov;12(9):1640-5.

10 Liu RH. Do behavioral interventions delivered before bariatric surgery impact weight loss in adults? A systematic scoping review. Bariatr Surg Pract Patient Care. 2016;11(2):39-48.

11 Wee CC, Pratt JS, Fanelli R, Samour PQ, Trainor LS, Paasche-Orlow MK. Best practice updates for informed consent and patient education in weight loss surgery. Obesity (Silver Spring). 2009 May;17(5):885-8.

12 Robinson AH, Adler S, Stevens HB, Darcy AM, Morton JM, Safer DL. What variables are associated with successful weight loss outcomes for bariatric surgery after 1 year? Surg Obes Relat Dis. 2014 Jul-Aug;10(4):697-704.

13 White MA, Kalarchian MA, Levine MD, Masheb RM, Marcus MD, Grilo CM. Prognostic Significance of Depressive Symptoms on Weight Loss and Psychosocial Outcomes Following Gastric Bypass Surgery: A Prospective 24-Month Follow-Up Study. Obes Surg. 2015 Oct;25(10):1909-16.

14 Köhler H, Dorozhkina R, Gruner-Labitzke K, de Zwaan M. Questionnaire to evaluate specific health knowledge of bariatric and metabolic surgery patients; 2015. Available from: www.heh-bs.de/fileadmin/user_upload/ documents/Downloads/Chirurgische_Klinik/Knowledge_test_and_correct_answers_for_bariatric_and_metabolic_surgery_patients.pdf [cited October 9, 2019]. 
15 Jordan S, Hoebel J. Health literacy of adults in Germany: Findings from the German Health Update (GEDA) study. Bundesgesundheitsblatt Gesundheitsforschung Gesundheitsschutz. 2015 Sep;58(9):942-50. German.

16 Löwe B, Kroenke K, Herzog W, Gräfe K. Measuring depression outcome with a brief self-report instrument: sensitivity to change of the Patient Health Questionnaire (PHQ-9). J Affect Disord. 2004 Jul;81(1):61-6.

17 Cassin S, Sockalingam S, Hawa R, Wnuk S, Royal S, Taube-Schiff M, et al. Psychometric properties of the Patient Health Questionnaire (PHQ-9) as a depression screening tool for bariatric surgery candidates. Psychosomatics. 2013 Jul-Aug; 54(4):352-8.

18 Löwe B, Decker O, Müller S, Brähler E, Schellberg D, Herzog W, et al. Validation and standardization of the Generalized Anxiety Disorder Screener (GAD-7) in the general population. Med Care. 2008 Mar;46(3):266-74.

19 Spitzer RL, Kroenke K, Williams JB, Löwe B. A brief measure for assessing generalized anxiety disorder: the GAD-7. Arch Intern Med. 2006 May;166(10):1092-7.

20 Reinhold RB. Critical analysis of long term weight loss following gastric bypass. Surg Gynecol Obstet. 1982 Sep; 155(3):385-94.

21 Taube-Schiff M, Chaparro M, Gougeon L, Shakory S, Weiland M, Warwick K, et al. Examining Nutrition Knowledge of Bariatric Surgery Patients: What Happens to Dietary Knowledge over Time? Obes Surg. 2016 May;26(5):972-82.

22 Bauchowitz A, Azarbad L, Day K, Gonder-Frederick L. Evaluation of expectations and knowledge in bariatric surgery patients. Surg Obes Relat Dis. 2007 Sep-Oct;3(5):554-8.

23 Madan AK, Tichansky DS. Patients postoperatively forget aspects of preoperative patient education. Obes Surg. 2005 Aug;15(7):1066-9.

24 Ledoux S, Sami O, Breuil MC, Delapierre M, Calabrese D, Msika S, et al. Relevance of Self-reported Behavioral Changes Before Bariatric Surgery to Predict Success After Surgery. Obes Surg. 2017 Jun;27(6):1453-9.

25 Orth WS, Madan AK, Ternovits CA, Tichansky DS. Effect of preoperative knowledge on weight loss after laparoscopic gastric bypass. Obes Surg. 2008 Jul;18(7):768-71.

26 Mangieri CW, Strode MA. Formal Nutritional Education Improves Weight Loss in Bariatric Patients Following Laparoscopic Sleeve Gastrectomy. Obes Surg. 2016 Dec;26(12):2952-60.

27 Kalarchian MA, Marcus MD, Courcoulas AP, Cheng Y, Levine MD. Preoperative lifestyle intervention in bariatric surgery: a randomized clinical trial. Surg Obes Relat Dis. 2016 Jan;12(1):180-7.

28 McGrice M, Don Paul K. Interventions to improve long-term weight loss in patients following bariatric surgery: challenges and solutions. Diabetes Metab Syndr Obes. 2015 Jun;8:263-74.

29 Groller KD. Systematic review of patient education practices in weight loss surgery. Surg Obes Relat Dis. 2017 Jun;13(6):1072-85.

30 Sørensen K, Van den Broucke S, Fullam J, Doyle G, Pelikan J, Slonska Z, et al.; (HLS-EU) Consortium Health Literacy Project European. Health literacy and public health: a systematic review and integration of definitions and models. BMC Public Health. 2012 Jan;12(1):80. 